John Carroll University

Carroll Collected

2018

\title{
Making a university community more dementia friendly through participation in an intergenerational choir.
}

Phyllis Braudy Harris

John Carroll University, pharris@jcu.edu

Cynthia A. Caporella

John Carroll University, ccaporella@jcu.edu

Follow this and additional works at: https://collected.jcu.edu/fac_bib_2018

Part of the Family, Life Course, and Society Commons, and the Gerontology Commons

\section{Recommended Citation}

Harris, Phyllis Braudy and Caporella, Cynthia A., "Making a university community more dementia friendly through participation in an intergenerational choir." (2018). 2018 Faculty Bibliography. 1.

https://collected.jcu.edu/fac_bib_2018/1 


\title{
Making a university community more dementia friendly through participation in an intergenerational choir
}

\author{
Phyllis Braudy Harris \\ Department of Sociology \& Criminology, John Carroll University, USA
}

\section{Cynthia Anne Caporella}

Department of Liturgical Music and Musical Arts, John Carroll

University, USA

\begin{abstract}
A dementia friendly community is one that is informed about dementia, respectful and inclusive of people with dementia and their families, provides support, promotes empowerment, and fosters quality of life. This study presents data from four cohorts of undergraduate college students and people with dementia and their family members, using an intergenerational choir as the process through which to begin to create a dementia friendly community. This was accomplished by breaking down the stereotypes and misunderstandings that young adults have about people with dementia, thus allowing their commonalities and the strengths of the people living with dementia to become more visible. Data were gathered for each cohort of students through semi-structured open-ended questions on attitudes about dementia and experiences in the choir, collected at three points over I0 weeks of rehearsals. Data about their experiences in the choir were collected from each cohort of people with dementia and their family members through a focus group. Results across all four cohorts showed in the students: changed attitudes, increased understanding about dementia and the lived experience, reduced dementia stigma, and the development of meaningful social connections. People with dementia and their family members expressed feelings of being part of a community.
\end{abstract}

\section{Keywords}

dementia friendly community, dementia stigma, Alzheimer's disease, creative arts, music, intergenerational

\section{Corresponding author:}

Phyllis Braudy Harris, Department of Sociology \& Criminology, John Carroll University, University Heights, OH 44II8, USA.

Email: pharris@jcu.edu 
"I expected fear from the students because of not knowing about AD, but they were open and empathetic, and perceived us as, 'We, not them.”' (A 72-year-old intergenerational choir member with early stage dementia.)

What makes a community dementia friendly? There is no agreed upon gold standard. It could be aspects of a community's physical environment, social environment, and culture. When discussing definitions of dementia friendly communities, characteristics most often included are that community members are: informed about dementia, respectful and inclusive of people with dementia and their families, provide support, promote empowerment, and foster quality of life. This study presents data from four cohorts of undergraduate college students and people with dementia and their family members, using an intergenerational choir as the process through which to begin to create a dementia friendly community. This was accomplished by breaking down the stereotypes and misunderstandings that young adults have about people with dementia, thus allowing their commonalities and the strengths of the people living with dementia to become more visible. Moreover, by participating in this experience choir members were able to reach across the boundaries of age, disabilities, and abilities to develop meaningful friendships.

\section{Public health crisis and dementia friendly communities}

The number of people living with dementia worldwide is currently estimated to be 47 million and is projected to increase to 131 million in 2050, and most countries lack an awareness and understanding of dementia. Thus, dementia is now being recognized worldwide as a public health crisis (Alzheimer's Disease International (ADI), 2016a; World Health Organization and Alzheimer's Disease International (WHO/ADI), 2012). This lack of knowledge about dementia results in the stigmatization of people with dementia and their family members, creates barriers to diagnosis and quality care, and impacts societies socially and economically. The cost of health care and long-term care of people with Alzheimer's disease and other dementias in the US alone is estimated to be $\$ 259$ billion dollars, and costs worldwide are projected to increase to a trillion dollars by 2018 (Alzheimer's Association, 2017; ADI, 2016a). Thus, the need to mobilize on a community wide basis and take more of a public health approach is being championed at a national level. Many countries have developed national dementia plans, such as the UK, Scotland, Ireland, US, Japan, Norway, Germany, Belgium, etc. (Department of Health UK, 2009; Henwood \& Downs, 2014; Ministry of Health and Care Services, 2008; Scottish National Health Services, 2010; US Department of Health and Human Services, 2012). The development of the dementia friendly communities' movement is an outgrowth of this growing concern and acknowledgement. Some of the national plans even include the term "dementia friendly" (Lin \& Lewis, 2015).

The overall goal of dementia friendly communities is to better the lives of people living with dementia and their family members, and to empower them to continue to be contributing members of society (ADI, 2016b). The theoretical frameworks upon which this stance draws are the social model of disability (Oliver, 1990) and Kitwood's work on personcentered care (1997). Both emphasize the role the environment (community) can have on a disabled person's ability to live well because of the dehumanizing and depersonalizing effect of stigma (Henwood \& Downs, 2014). This stigma leads to social exclusion, marginalization, and feelings of otherness experienced by both people living with dementia and by association their families (ADI, 2012; Downs, 2013; Harris \& Caporella, 2014; 
Werner \& Heinik, 2008). Thus, there is broad agreement among the national plans and Alzheimer's organizations that one of the first issues to address in building a dementia friendly community is the need to confront dementia stigma (Alzheimer's Society, 2013; Dementia Friendly America, 2017).

\section{Dementia stigma}

The stigmatizing process was first delineated by Goffman (1963). It was described as a process where social meaning, with negative connotations, was attached to behaviors and individuals. Stigma comes from a Greek word which describes attributes that indicate something out of the ordinary or bad about a person. It causes an individual to be judged by others as undesirable, "not normal," thus leading to stereotyping and rejection. As the person with the "stigmatizing condition" becomes more linked with that label, that label becomes the defining characteristic of that person with far reaching personal and societal consequences.

People living with dementia can attest to this stigmatizing process. For example, Kate Swaffer, a person living with dementia has stated, "Following a diagnosis of dementia, most health care professionals prescribe giving up a pre-diagnosis life and put all the planning in place for the demise of the person newly diagnosed with dementia. I was told to give up work, give up study, and to go home and live for the time I had left. Dementia is the only disease or condition and the only terminal illness that I know of where patients are told to go home and give up their pre-diagnosis lives, rather than to "fight for their lives" (Swaffer, 2015, p. 3). Another person living well with dementia has also written, "I have found that some people who are really keen to make their communities better places for people living with dementia, want to adapt in any way they can-be it their business premises or their places of worship. But sadly, there are still folk out there who are reluctant to embrace any idea of becoming dementia friendly. This thinking could make me angry, but I have to realize that there is still a lot of ignorance out there and a fair bit of stigma. It wasn't that many years ago that we avoided talking about cancer - the 'big C' or AIDS and how frightening it was. But now both these issues are not the scary undiscussed topics they once were. So let's make dementia a topic that can be embraced rather than feared and help those of us living with it to live well" (Watson, 2016, p. 5).

Dementia stigma is such a worldwide concern that ADI devoted their total, 2012 World Report to discussing the stigma of dementia. The report used survey data from over 2,500 people with dementia and family members from 54 countries. The data showed overwhelmingly that both people with dementia and family members believed that there are negative associations for those diagnosed with dementia and their care partners (ADI, 2012). This stigma leads to serious consequences such as delayed diagnosis and treatment (Cahill, Clark, O'Connell, Lawlor, Coen, \& Walsh, 2008; VernoojiDassen, Moniz-Cook, Woods, De Lepeleire, Leuschner, \& Zanetti, 2005), and delayed seeking of care (Dobbs, Eckert, Rubenstein, Keimig, Clark, \& Frankowski, 2008; Justiss, Boustani, Fox, Perkins, \& Healey, 2009; Robinson, Canavan, \& O’Keeffie, 2014).

\section{Dementia stigma, dementia friendly communities, and the creative arts}

Dementia stigma, one of the first steps to combat in building a dementia friendly community, can be challenged through a number of different approaches and on a number of different 
structural levels. Bartlett (2016) discusses some national approaches for building dementia friendly communities, all which include some aspects of dementia stigma. For example, in the United States, there is the Minnesota Tool Kit for making a community more dementia friendly, which includes becoming educated about dementia; this is part of the Act on Alzheimer's Movement (Act on Alzheimer's, 2017). On a large corporate level, Heathrow airport in London has become the first airport to be designated dementia friendly, which entails educating their workforce about dementia to break down stereotypes so people with dementia feel understood and included. This was part of the Prime Minister's, 2020 Challenge on Dementia to the businesses community (Heathrow Press release, 2017).

Addressing dementia stigma through community building can also be done on a micro level, by bringing small disparate groups of people together to work toward the common goal of lessening the stigma. This is based on intergroup contact theory that was first proposed by Gordon Allport (1954) in his seminal work on the nature of prejudice. The main concepts of the theory are that contact between different groups under optimal conditions, such as equal status among the group members, common goals, and intergroup cooperation with consistent and meaningful contact, can reduce intergroup prejudice. The creative arts is one approach that has the capability of accomplishing this psychosocial process. As de Medeiros and Basting (2013) have stated, the cultural arts have the potential to promote social and behavioral change in people. A goal of cultural arts interventions is to create meaningful experiences and promote social connections, that could be used to reach across the barriers of age, race, gender, disabilities, and other dividing social constructs to assist in community building (Burnside, Knecht, Hopely, \& Logsdon, 2017; de Medeiros \& Basting, 2013; Harris \& Caporella, 2014). Music, as one of the creative arts, can be a vehicle that can foster social cohesion, contact, and relationship building, as has been shown with people with dementia and their family members (Camic, Williams, \& Meeten, 2013; Hays \& Minichiello, 2005; McDermett, Orrell, \& Ridder, 2014; Sixsmith \& Gibson, 2007; Unadkat, Camic, \& Vella-Burrows, 2016). Dowlen et al. (2017) suggest that the meaningful social interactions and connections that musical activities foster enables the person with dementia to feel a sense of security and a sense of belonging. Thus, providing them an opportunity to feel part of a community. In addition, O'Connor and McFadden (2010) found contact with people with dementia can produce positive attitude change, especially when these relationships occur in programs that encourage creative expression. For example, Reynolds, Innes, Poyner, and Hanbidge (2017) found that public orchestral performances by people with dementia and their carers had a positive impact on the audience's public perceptions of dementia.

This study on creating a more dementia friendly community focuses on a small university campus. College students, like the rest of the public, have many misunderstandings and stereotypes about people with dementia (Lundquist \& Ready, 2008; Sabat, 2011). Yet young adults attitudes toward older adults can be positively affected by meaningful interactions with older adults (Grefe, 2010; Loe, 2013; Newman, Faux, \& Larimer, 1997; Thompson \& Weaver, 2016). An intergenerational choir was chosen as the vehicle through which to start community building with this population. A choir was chosen for four reasons: (1) a choir by virtue of its nature can: reduce isolation, build community, give people a voice, and educate through intergroup exposure and public presentation; (2) a choir can reduce prejudice based on the psychosocial theory of intergroup contact, (3) music has the power to bring people together and promote social connectedness, and (4) by participating in the intergenerational choir and interacting with the choir members with dementia and their 
families, students would be exposed to "the lived experience of dementia" (a much more powerful experience than just reading books about dementia).

Thus, in order to start creating a more dementia friendly college community three components of stigma need to be addressed: (a) knowledge (ignorance), (b) attitudes, and (c) behavior. Therefore, the three research questions that guided this study were:

1. Could participation by college students in an intergenerational choir with people with dementia and their family members: lessen misunderstandings about people with dementia, increase student's knowledge about the lived experience of dementia, and assist students in recognizing the capabilities of people living with dementia?

2. Could meaningful social connections between the choir members be developed that would reach across the barriers of age, disabilities, and abilities?

3. Could these findings be replicated across different cohorts?

\section{Methods}

\section{Research design}

Since dementia friendly communities is a relatively new area of inquiry, a phenomenological qualitative approach was used to gather data, primarily drawing on the writings of Holstein and Gubrium (1994) and Schutz (1967, 1970). A qualitative phenomenological method is particularly useful when there is limited knowledge about a phenomenon. This means that this inductive approach begins with individual experiences described through their words, and the findings are located within a specific context. Thus, in the context of this study, the words of the choir members were used to explain their experiences from participating in the choir.

Sample. Each spring term for four years (2013, 2014, 2015, and 2017) an intergenerational choir was formed, thus there were four different cohorts. The people with dementia and family members were recruited through the local Alzheimer's Association chapter by letters and announcements at their support group meetings. The inclusion criteria for the people with dementia were: (1) a diagnosis of early stage dementia or mild cognitive impairment, (2) membership in one of the Associations' early stage support groups, (3) enjoyment of singing, and (4) commitment to attend the 10 weeks of rehearsals and the concluding performance.

The college students were recruited through announcements made in an aging studies course, e-mails sent to students who had participated in musical events on campus, an announcement in the e-newsletter of the university's center for service, and by word of mouth by the students. Any interested student had to be separately screened by the researcher and the choir director. Criteria for inclusion were: (1) full-time undergraduate student or recent alumni, (2) prior experience singing in a choir, (3) no knowledge or experience with dementia was necessary, (4) commitment to attend the 10 weeks of rehearsals and the concluding performance, and (5) attendance at an hour orientation/information session about dementia before the choir rehearsals began.

In year 1 , there were 13 undergraduate college students and 13 people with early stage dementia and their family members. In year 2, there were 12 college students and 10 people with dementia and their family members. In year 3, there were 19 college students and 10 people with dementia and their family members. In year 4, there were 18 college students and 10 people with dementia and their family members. For a total of $N=62$ college 
Table I. Student demographics $(N=62)$.

\begin{tabular}{|c|c|c|c|c|c|c|c|c|c|c|}
\hline \multirow[b]{2}{*}{ Characteristic } & \multicolumn{2}{|c|}{$\begin{array}{l}\text { Cohort I } \\
(N=13)\end{array}$} & \multicolumn{2}{|c|}{$\begin{array}{l}\text { Cohort } 2 \\
(N=12)\end{array}$} & \multicolumn{2}{|c|}{$\begin{array}{l}\text { Cohort } 3 \\
(N=19)\end{array}$} & \multicolumn{2}{|c|}{$\begin{array}{l}\text { Cohort } 4 \\
(N=18)\end{array}$} & \multicolumn{2}{|c|}{$\begin{array}{l}\text { Total } \\
(N=62)\end{array}$} \\
\hline & $N$ & $\%$ & $N$ & $\%$ & $N$ & $\%$ & $N$ & $\%$ & $N$ & $\%$ \\
\hline \multicolumn{11}{|l|}{ Year } \\
\hline $\mathrm{Fr}$ & 5 & 38 & 0 & 0 & 5 & 26 & 7 & 39 & 17 & 27 \\
\hline So & 3 & 23 & 2 & 17 & 1 & 5 & 2 & II & 8 & 13 \\
\hline $\mathrm{Jr}$ & 1 & 8 & 4 & 34 & 6 & 32 & 5 & 28 & 16 & 26 \\
\hline $\mathrm{Sr}$ & 4 & 31 & 5 & $4 I$ & 5 & 26 & 2 & 11 & 16 & 26 \\
\hline Recent alumni & 0 & 0 & 1 & 8 & 2 & 11 & 2 & II & 5 & 8 \\
\hline \multicolumn{11}{|l|}{ Age } \\
\hline Mean & \multicolumn{2}{|c|}{19.8} & \multicolumn{2}{|l|}{21.2} & \multicolumn{2}{|l|}{20.7} & \multicolumn{2}{|l|}{20.2} & \multicolumn{2}{|l|}{20.5} \\
\hline Range & \multicolumn{2}{|c|}{$18-22$} & \multicolumn{2}{|c|}{$19-24$} & \multicolumn{2}{|c|}{$18-29$} & \multicolumn{2}{|l|}{$18-26$} & \multicolumn{2}{|l|}{$18-29$} \\
\hline \multicolumn{11}{|l|}{ Gender } \\
\hline Female & 13 & 100 & 10 & 83 & 16 & 84 & 17 & 94 & 39 & 87 \\
\hline Male & 0 & 0 & 2 & 17 & 3 & 16 & 1 & 6 & 5 & 13 \\
\hline \multicolumn{11}{|l|}{ Major } \\
\hline Business & 2 & 15 & 0 & 0 & 4 & 21 & 6 & 33 & 12 & 19 \\
\hline Science & 2 & 15 & 6 & 50 & 8 & 42 & 6 & 33 & 22 & 35 \\
\hline Undecided & I & 8 & 0 & 0 & 2 & 11 & 0 & 0 & 3 & 5 \\
\hline Social sciences & 6 & 46 & 4 & 34 & 4 & 21 & 5 & 28 & 19 & 31 \\
\hline Humanities & 2 & 15 & 1 & 8 & 0 & 0 & 0 & 0 & 3 & 5 \\
\hline Religion/Philosphy & 0 & 0 & 1 & 8 & I & 5 & I & 6 & 3 & 5 \\
\hline \multicolumn{11}{|c|}{ Knows someone who has AD } \\
\hline Yes & 4 & 31 & 10 & 83 & 16 & 84 & 10 & 56 & 40 & 65 \\
\hline No & 9 & 69 & 2 & 17 & 3 & 16 & 8 & 54 & 22 & 35 \\
\hline \multicolumn{11}{|l|}{ Absences } \\
\hline 0 & 8 & 61 & 3 & 25 & 6 & 32 & 14 & 77 & 31 & 41 \\
\hline 1 & 4 & 31 & 4 & 34 & 10 & 52 & I & 6 & 19 & 39 \\
\hline 2 & 1 & 8 & 3 & 25 & 2 & 11 & 1 & 6 & 8 & 13 \\
\hline 3 & 0 & 0 & 1 & 8 & I & 5 & I & 6 & 2 & 5 \\
\hline $4+$ & 0 & 0 & I & 8 & 0 & 0 & 1 & 6 & 2 & 2 \\
\hline
\end{tabular}

AD: Alzheimer's disease.

students and $N=43$ people with dementia and family members over the four years. In year 2 , three students returned to join the choir again, and three people with dementia and their family members; in year 3, seven students returned and two people with dementia and their family members; in year 4 , four students returned and three people with dementia and their family members.

Table 1 shows the demographic characteristics of all the students by cohort. Totally among the student choir members $87 \%$ were female, with a mean age 20.5 years and a range of 18-29 years old. Sixty-five percent knew someone with AD (a family member or family friend). Of the 62 students, $27 \%$ were freshmen, $13 \%$ were sophomores, $26 \%$ were juniors, $26 \%$ were seniors, and $(8 \%)$ were alumni. Their major fields of study were very varied. Attendance at the rehearsals was very good across the four cohorts, with $(80 \%)$ of the students missing no more than one rehearsal. Each year there were some differences in the distribution of the students across classes, majors, and exposure to people with 
Table 2. People with dementia and family member demographics $(N=43)$.

\begin{tabular}{|c|c|c|c|c|c|c|c|c|c|c|}
\hline \multirow{2}{*}{$\begin{array}{l}\text { Characteristics of } \\
\text { people with dementia }\end{array}$} & \multicolumn{2}{|l|}{$\begin{array}{l}\text { Cohort I } \\
(N=6)\end{array}$} & \multicolumn{2}{|l|}{$\begin{array}{l}\text { Cohort } 2 \\
(N=5)\end{array}$} & \multicolumn{2}{|l|}{$\begin{array}{l}\text { Cohort } 3 \\
(N=6)\end{array}$} & \multicolumn{2}{|l|}{$\begin{array}{l}\text { Cohort } 4 \\
(N=5)\end{array}$} & \multicolumn{2}{|l|}{$\begin{array}{l}\text { Total } \\
(N=22)\end{array}$} \\
\hline & $N$ & $\%$ & $N$ & $\%$ & $N$ & $\%$ & $N$ & $\%$ & $N$ & $\%$ \\
\hline \multicolumn{11}{|l|}{ Gender } \\
\hline Female & 3 & 50 & 3 & 60 & 4 & 66 & 3 & 60 & 13 & 59 \\
\hline Male & 3 & 50 & 2 & 40 & 2 & 34 & 2 & 40 & 9 & 41 \\
\hline \multicolumn{11}{|l|}{ Race } \\
\hline White & 5 & 84 & 3 & 60 & 2 & 33 & 3 & 60 & 13 & 59 \\
\hline Black & 1 & 16 & 2 & 40 & 4 & 67 & 2 & 40 & 9 & 41 \\
\hline $\begin{array}{l}\text { Mean age } \\
\text { Education }\end{array}$ & 72 & & 70 & & 70 & & 75 & & 72 & \\
\hline College Grad & 6 & 100 & 4 & 80 & 3 & 50 & 4 & 80 & 17 & 77 \\
\hline \multicolumn{11}{|l|}{ Type of dementia } \\
\hline$A D$ & 5 & 84 & 3 & 60 & 3 & 50 & 3 & 60 & 14 & 64 \\
\hline $\mathrm{MCl}$ & I & 16 & 1 & 20 & 1 & 16 & I & 20 & 4 & 18 \\
\hline PPA & 0 & 0 & 1 & 20 & I & 16 & 0 & 0 & 2 & 9 \\
\hline Lewy body & 0 & 0 & 0 & 0 & 1 & 16 & 1 & 20 & 2 & 9 \\
\hline $\begin{array}{l}\text { Characteristics of } \\
\text { family members }\end{array}$ & $(N=7)$ & $\%$ & $(N=5)$ & $\%$ & $(N=4)$ & $\%$ & $(N=5)$ & $\%$ & $(N=2 I)$ & $\%$ \\
\hline \multicolumn{11}{|l|}{ Relationships } \\
\hline Spouse & 5 & 70 & 3 & 60 & 3 & 75 & 4 & 80 & 15 & 71 \\
\hline Daughter & 0 & 0 & 1 & 20 & I & 25 & I & 20 & 3 & 14 \\
\hline Son & I & 15 & 0 & 0 & 0 & 0 & 0 & 0 & I & 5 \\
\hline Grandchild & I & 15 & I & 20 & 0 & 0 & 0 & 0 & 2 & 10 \\
\hline \multicolumn{11}{|l|}{ Gender } \\
\hline Female & 4 & 57 & 4 & 80 & 3 & 75 & 3 & 60 & 14 & 67 \\
\hline Male & 3 & 43 & I & 20 & I & 25 & 2 & 40 & 7 & 33 \\
\hline Mean age & 72 & & 56 & & 67 & & 65 & & 65 & \\
\hline \multicolumn{11}{|l|}{ Race } \\
\hline White & 6 & 86 & 2 & 40 & 2 & 50 & 4 & 75 & 14 & 67 \\
\hline Black & 1 & 14 & 3 & 60 & 2 & 50 & I & 25 & 7 & 33 \\
\hline College Grad & 6 & 85 & 4 & 80 & 3 & 75 & 5 & 100 & 15 & 71 \\
\hline
\end{tabular}

AD: Alzheimer's disease; $\mathrm{MCl}$ : mild cognitive impairment; PPA: primary progressive aphasia.

dementia, so the choir in this way was composed of a variety of students. However, each year the choir was composed of predominately women (as was typical of other musical groups on campus) and variance in the mean age was small.

Table 2 shows the demographic characteristics of the people living with dementia and their families. Over the four cohorts, 43 people living with dementia and their family members participated, with some people and family members participating more than once, as mentioned above. As regards the people with dementia, 59\% were female, 59\% were White and $41 \%$ Black, the mean age was 72 , the most common diagnosis was early stage Alzheimer's disease, and $77 \%$ were college graduates. For the family members, the majority were spouses $(71 \%), 67 \%$ were female, $67 \%$ were White and $33 \%$ were Black, mean age was 65 , and $71 \%$ were college educated. 


\section{Procedures and choir structure}

The study was approved each year by the University's IRB Committee for the Protection of Human Subjects before the recruitment started. Once the students were recruited, they attended a mandatory one-hour orientation/information session on dementia and the experience of living with dementia. Also the researcher attended all the choir rehearsals to be available for questions and handle any concerns. In addition, the researcher called the Alzheimer's Association support group members, who were joining the choir, to answer any questions or concerns they might have. During this time, the researcher and choir director were meeting, calling, and e-mailing frequently to plan how to structure the choir to foster social interaction, to select the musical repertoire, and to discuss possible challenges that might arise and how best to handle them. It was also decided that the choir's concert would be tied to an annual Alzheimer's disease educational event organized for the community. In keeping with intergroup contact theory, it was important to have a shared goal (the concert) for the choir to work toward. The choir met weekly for 10 weeks with rehearsals lasting for 90 minutes before the concert date.

In order to build connections between the student and the people living with dementia and their family members, it was essential to foster social interaction and contact. Therefore, a great deal of thought went into how best to accomplish this. The following structure was used: (1) the choir, instead of usually sitting on risers in front of the choir director, sat more informally in a circle, so everyone faced each other; (2) students, starting with the first rehearsal, were "buddied up" with a person with dementia and their family members, and they sat next to each other during most of the rehearsals, and this was explained to the students during their orientation session, and ideas for possible conversation topics were suggested; (3) at the beginning of each rehearsal, time was given (15-20 minutes) for socialization, a chance for the "buddies" to talk with each other; (4) after the socialization time, the researcher would take five minutes to update the choir, make announcements, and answer any questions. This was always done in a light, upbeat manner; and (5) the choir director, who also used an upbeat and humorous approach, had the group do a few minutes of warm-up stretching exercises that included physical contact, before starting the singing.

Crucial to the structure of the choir and social interaction, all choir members were treated as equals and called by their first names, regardless of the age difference. Name tags were used for every rehearsal. In addition, the setting of the tone for the choir was introduced during the first rehearsal; it was that of acceptance, being non-judgmental, working as a team ("we are all in this together"), and having fun. Everyone knew the purpose of the choir. Humorous ice-breaking techniques were used during the socialization period of the first rehearsals for everyone to get to know each other.

Music repertoire. The selection of the music was critical for the message of the choir to come across. The choir was intergenerational, with the specific goal of making a college community more dementia friendly through building connections between groups of people and increasing students' understanding about dementia. Also through the choir's public performance, the larger community's misunderstandings about dementia and the capabilities of people with dementia could be challenged. Thus, the songs chosen had to encourage and foster connections, appeal to both generations, and if not familiar, be easy to learn. Much discussion between the choir director and researcher took place around the choice of music. The researcher was particularly interested in the "message" or text of 
the music. The choir director in addition to the message, was also very cognizant about how "wordy" a song would be, looking for songs with: more repetition, fewer rhythmic changes, and ones which were clearly laid out on a page. It took a few trials and errors to find the right songs, and it was decided that learning five songs for each cohort would be the goal. Some of the songs decided upon were: "Stand by Me", "If You Need a Friend", "We Shall Overcome.", "Ain't No Mountain High Enough", "Somewhere Over the Rainbow", and "Stand by You."

Data collection. Data for the college students were collected each year through a repeated measure design with a pre-test (T1), a test half way through (T2), and a post-test (T3) after the concert. At T1 and again at T3 the students were asked: "When you hear the word Alzheimer's disease or dementia, what images come to mind? Please write down 10 words that describe those images." And they were also asked, "If your parent asked you to spend an afternoon with a family friend who has Alzheimer's disease, would you feel comfortable doing it?" In addition, at T2 and T3, students were asked to respond to open-ended questions, such as: (1) What have you learned about dementia, people living with dementia, and their family members so far from this experience? (2) What has surprised you the most from this experience? (3) Has this experience changed your ideas/images of people with dementia and their family members? (4) Do you feel more comfortable around people with dementia? And (5) Do you feel you have developed a connection or bond with the intergenerational choir members who have dementia? If so, what do you think has caused this connection to occur? For all questions, the students were asked to describe their thoughts, reactions, and feelings in detail. Data were collected each year from the people with dementia and their family members through a focus group held during week 6 or 7. Since the dementia friendly field is in its infancy, there are no well accepted standard measures.

Data analysis. The college students had two sets of data: (1) the 10 descriptors of dementia collected at T1 and T3, and (2) the open-ended questions asked at T2 and T3. For the students who participated in the choir for more than one year, after the first year their responses were not included in the data analysis at T1 and T3. The responses to the opened-ended questions were analyzed by examining common themes that emerged from the questions at T2 and T3 across all four years, and comparing them. In order to be considered a common theme, it had to have been mentioned by at least $50 \%$ of the students, and quotations were then selected that captured the essence of the themes across all four years.

For the focus group with the people living with dementia and their family members, the focus groups were taped with permission. The tapes were transcribed and then compared with field notes for accuracy. The analysis consisted of a four step process: (1) the entire transcripts were read in its entirety by both authors separately, (2) the transcripts were reread by the authors to develop substantive codes for the narratives, (3) the codes were compared and any discrepancies were discussed in order to come to consensus, (4) the codes were grouped into themes related to the building of social connections with the students and their experience in the choir. In order to be considered a common theme, it had to have been mentioned by at least $50 \%$ of the focus group members, and (5) quotations were selected that captured the essence of those themes across all four years. 
Table 3. Cohort I students' attitudinal responses.

\begin{tabular}{llll}
\hline Score & TI $(N=13)^{\mathrm{a}}$ & T3 $(N=12)^{\mathrm{a}}$ & \% Change \\
\hline Negative & $60 \%(N=78)^{\mathrm{b}}$ & $18 \%(N=22)^{\mathrm{b}}$ & $-42 \%$ \\
Neutral & $25 \%(N=32)^{\mathrm{b}}$ & $17 \%(N=20)^{\mathrm{b}}$ & $-8 \%$ \\
Positive & $15 \%(N=20)^{\mathrm{b}}$ & $65 \%(N=78)^{\mathrm{b}}$ & $+50 \%$ \\
\hline
\end{tabular}

${ }^{\mathrm{a}}$ Number of students.

${ }^{b}$ Number of responses.

Table 4. Cohort II students' attitudinal responses.

\begin{tabular}{llll}
\hline Score & TI $(N=9)^{\mathrm{a}}$ & T3 $(N=9)^{\mathrm{a}}$ & $\%$ Change \\
\hline Negative & $66 \%(N=59)^{\mathrm{b}}$ & $11 \%(N=9)^{\mathrm{b}}$ & $-55 \%$ \\
Neutral & $23 \%(N=21)^{\mathrm{b}}$ & $9 \%(N=7)^{\mathrm{b}}$ & $-14 \%$ \\
Positive & $11 \%(N=10)^{\mathrm{b}}$ & $80 \%(N=64)^{\mathrm{b}}$ & $+69 \%$ \\
\hline
\end{tabular}

${ }^{\mathrm{a}}$ Number of new students.

b Number of responses.

Table 5. Cohort III students' attitudinal responses.

\begin{tabular}{llll}
\hline Score & TI $(N=12)^{\mathrm{a}}$ & T3 $(N=12)^{\mathrm{a}}$ & \% Change \\
\hline Negative & $69 \%(N=82)^{\mathrm{b}}$ & $13 \%(N=15)^{\mathrm{b}}$ & $-56 \%$ \\
Neutral & $11 \%(N=13)^{\mathrm{b}}$ & $12 \%(N=14)^{\mathrm{b}}$ & $+1 \%$ \\
Positive & $20 \%(N=23)^{\mathrm{b}}$ & $75 \%(N=87)^{\mathrm{b}}$ & $+55 \%$ \\
\hline
\end{tabular}

${ }^{\mathrm{a} N u m b e r}$ of new students.

${ }^{b}$ Number of responses.

\section{Findings}

\section{College students}

Changed attitudes/images of dementia. Looking at the trend and direction in the change in students' attitudes toward people with dementia across all four cohorts, participating in the intergenerational choir appeared to have an effect (See Tables 3-7). At T1 and T3, students were asked to describe their images of people with dementia, using 10 words. These words were scored as negative, neutral, or positive. At T1 some examples of the most common negative words chosen by the students were: sadness, nursing home, sick, helplessness, memory loss, forgetfulness, depression, loss of brain function, frustration, dependency, deterioration, and confusion; examples of neutral words were: elderly, senior citizens, older adults, The Notebook, doctors, medicine; and examples of positive words: unity, caring families, love, patience, and tolerance.

At T1 for all four cohorts, the responses were overwhelmingly negative (See Tables 3-6). For cohort one, $N=130$ responses (13 students $\times 10$ responses) $60 \%$ were negative and only $15 \%$ were positive. For cohort two, $66 \%$ were negative and $11 \%$ were positive. For cohort three, $69 \%$ were negative and $20 \%$ were positive. And for cohort four, $61 \%$ were negative 
Table 6. Cohort IV students' attitudinal responses.

\begin{tabular}{llll}
\hline Score & TI $(N=12)^{\mathrm{a}}$ & T3 $(N=12)^{\mathrm{a}}$ & $\%$ Change \\
\hline Negative & $61 \%(N=74)^{\mathrm{b}}$ & $19 \%(N=23)^{\mathrm{b}}$ & $-42 \%$ \\
Neutral & $23 \%(N=26)^{\mathrm{b}}$ & $16 \%(N=19)^{\mathrm{b}}$ & $-7 \%$ \\
Positive & $16 \%(N=20)^{\mathrm{b}}$ & $65 \%(N=78)^{\mathrm{b}}$ & $+49 \%$ \\
\hline
\end{tabular}

${ }^{\mathrm{a} N u m b e r}$ of new students.

${ }^{\mathrm{b}}$ Number of responses.

Table 7. Total students' attitudinal responses.

\begin{tabular}{llll}
\hline Score & TI $(N=46)^{\mathrm{a}}$ & T3 $(N=46)^{\mathrm{a}}$ & \% Change \\
\hline Negative & $64 \%(N=293)^{\mathrm{b}}$ & $15 \%(N=69)^{\mathrm{b}}$ & $-49 \%$ \\
Neutral & $20 \%(N=92)^{\mathrm{b}}$ & $14 \%(N=63)^{\mathrm{b}}$ & $-6 \%$ \\
Positive & $16 \%(N=73)^{\mathrm{b}}$ & $71 \%(N=326)^{\mathrm{b}}$ & $+55 \%$ \\
\hline
\end{tabular}

${ }^{\mathrm{a}}$ Number of new students.

${ }^{\mathrm{b}}$ Number of responses.

and $16 \%$ were positive. The results were very similar across all four cohorts. Aggregating all the data (See Table 7), totally at T1 $64 \%$ of the responses were negative and $16 \%$ were positive.

By T3, there was a major change in the students' attitudes. For cohort one, $N=120$ (12 students $\times 10) 18 \%$ of the responses were negative, a change of $42 \%$, and $65 \%$ were positive, a change of $50 \%$. For cohort two, $11 \%$ of the responses were negative, a change of $55 \%$, and $80 \%$ were positive, a change of $69 \%$. For cohort three, $13 \%$ of the responses were negative, a change of $56 \%$, and $75 \%$ were positive, a change of $55 \%$. For cohort four, $19 \%$ of the responses were negative, a change of $42 \%$, and $65 \%$ were positive, a change of $49 \%$. Again the trend and directions of the results were similar across all four cohorts. Aggregating all the data, totally at T3, 15\% of the responses were negative, a change of $49 \%$, and $71 \%$ were positive, a change of $55 \%$. In addition, at $\mathrm{T} 3$ the range of positive descriptors also increased to include such words as: helping, joking, laughing, needing guidance but not assistance, love of life, learning, determination, hope, remaining positive, and friends. Therefore it appears that participating in an intergenerational choir has the potential impact of changing college students' negative attitudes/images of people with dementia.

Qualitative themes. The themes that emerged from the open-ended questions asked of the students at T2 and T3 across all four cohorts also supports the changes discussed above. There were four common themes that emerged from the data: (1) an expanded understanding of dementia and the lived experience, (2) reduced dementia stigma by the breaking down of stereotypes, (3) recognition of the capabilities of people living with dementia, and (4) development of meaningful social connections.

Expanded understanding of dementia and the lived experience. By participating in the intergenerational choir, students in all the cohorts discussed how the experience had increased their 
awareness of dementia and their understanding about living with dementia. Below are just a few of the examples of the students' responses from each cohort:

\section{Cohort 1}

"I have learned that people with $\mathrm{AD}$ are really no different from anyone else. This experience has changed the way I perceive people with AD; they can be just as funny and lively as any other person. It has made me put aside the fact that they have AD and treat them equally."

\section{Cohort 2}

"Months ago I was afraid of not knowing what to say or what to do [around a person with dementia]. But the issue was with me, not with the folks with memory loss. Now, I realize to be present is all that is necessary. We are not spending time with one another to run quizzes and see how much memory is left; rather, spending time with someone because that's what people do. We need to spend time with one another and that's what this choir has helped me to understand. Spending time with my new friends with Alzheimer's helped me to see that we are not hopeless when we start forgetting; we are hopeless when we give up and decide not to live."

\section{Cohort 3}

"People with Alzheimer's disease are just like anybody else. Sometimes people with Alzheimer's have a bad day and it might be more evident that the person has Alzheimer's. But people without Alzheimer's have bad days too, and may not act like they usually do. A person with Alzheimer's is still a person. A person having Alzheimer's disease does not change the fact that they are a human being and like to make connections. With the proper support, people with AD can really flourish and truly live their lives to their fullest capacity."

\section{Cohort 4}

"This experience has showed me that just because these people had AD does not mean that they stop living or that they can't do everyday tasks. It just means that they have a disease that they struggle with, but they aren't going to let it define them."

Reduced dementia stigma. By participating in the choir, students in all four cohorts were able to get beyond the label of dementia and see the person first, and come to realize the commonalities they shared. Through this process, societal stereotypes of dementia began to disappear.

\section{Cohort 1}

"I feel more comfortable around people with AD after participating in this choir. Working with these people made me realize that they are no different from any of us. Like students they love to laugh, make new friends, and so many things. There are times that I forget they have AD." 


\section{Cohort 2}

"The more time I spend with them, the more I realize the importance of seeing past the diagnosis and recognizing the inherent human dignity of the person with the disease."

\section{Cohort 3}

"This opportunity meant the world to me because I was able to break past stereotypes of AD, which I did not know I had. Having conversations and getting to know someone, the similarities appear. When similarities appear, a connection has been made. I will miss seeing everyone every Thursday because it was the highlight of my week."

\section{Cohort 4}

"The intergenerational choir may have meant a lot for the people we sing with, but I think it meant more to me to see how the relationships grew over time. The number one problem that clouds people with AD is society's focus on the later stages and the 'bad' problems associated with it. Society needs to focus on the 'positive' aspects as well. I also think more people in my generation should be exposed to people with AD to break the stereotypes associated with them."

Recognition of the capabilities. Meeting on a weekly basis, getting to know each other, and working together to learn the songs, the students began to recognize the strengths and capabilities of people living with dementia. For many, their admiration of the people's willingness not to give in to the disease resulted in seeing the people with dementia as role models.

\section{Cohort 1}

"Before this choir I thought how difficult life is for them and they probably are living in a senior center. I usually didn't consider how people with AD try not to let the disease define who they are. They don't let the disease hold them back. Their strength and hope is something I look up to."

\section{Cohort 2}

"Some people that have AD do not let the disease stop them. They continue with their normal life and enjoy the small things. When talking to these people every week, I can hear the determination in their voices. I hear their determination to not let the AD run their lives. I saw this when multiple people insisted that they would memorize the music, and they never missed a word when singing. Knowing they they are determined not to let AD control them is inspiring to me."

\section{Cohort 3}

"I have learned a lot from those with memory loss and their families. They are very brave, strong, and courageous people. They are dealing with something that can be very difficult and very emotional, yet they were not resigned. Instead of retreating, they decided to stand up and 
fight - for life, for love, for family, and for awareness. At least that is how I see it, no matter how cheesy it may sound. I think we all go through difficult things in life; it's how you react that sets you apart from others. The individuals I met through this choir were truly inspirational to me. I see them as role models for me, as well as others."

\section{Cohort 4}

"I have learned that people with $\mathrm{AD}$ are amazing, strong, and adaptable people. With having $\mathrm{AD}$ changes need to be made to the lifestyle to allow them to conquer $\mathrm{AD}$ and not let $\mathrm{AD}$ conquer them. Whether it is having to keep to strict routines or adding reminders to their phones; they find ways to live as normally as possible."

Development of meaningful social connections. Across the four cohorts, students were surprised by the meaningful connections they made with the people living with dementia and their family members, and the speed with which these occurred. Music seemed to be the vehicle that drew them together and fostered their developing friendships.

\section{Cohort 1}

"I originally joined the choir because I love to sing and service is important to me. But now I look forward to coming here every Thursday. It is the highlight of my week. We have so much fun and laugh together. These are my friends."

\section{Cohort 2}

"I was most surprised by the bonds that everyone formed through this experience. I did not realize until the night of the performance (when everyone was taking selfies and exchanging contact information) how close everyone had become. I came into this experience expecting to meet new people and have the opportunity to help people with Alzheimer's, but I was surprised to find that they had just as great an impact (if not greater) on me than I likely had on them."

\section{Cohort 3}

"I was surprised by how much they gave to me. Thursdays became a huge high point in my week. We were there to bring some light into their lives, but they really brought that into my life. I signed up as a shy freshman, who was still more than a little homesick. And I didn't really share that with the people in choir, but even so, they helped me an awful lot by their simple acts of caring. I was surprised by how much they mean to me and when they would talk about how much we mean to them, it was amazing. My family was at the concert and they said, 'I never looked happier while singing,' which I can believe. In all my years of singing, I have never cared about a group like I care about this one."

\section{Cohort 4}

"I was surprised by how close I got to the couple I was 'buddied' with. Even with her communication problems and the age difference, we were able to form a friendship I will treasure. 
After the performance, I did not get a chance to say goodbye to them. The next day they emailed me to say good-bye and thank me for caring I showed them. They definitely did not have to do that, but it showed me that I had made new friends. It was truly a community that accepted everyone for who they were."

From the narratives above, the progression of the students across all four cohorts in their understanding about dementia, their reduced misconceptions about the disease, their increased awareness of the strengths of people living with dementia, and their development of meaningful friendships becomes evident. Therefore, from both the assessment of the attitudes/images the students held about people with dementia and how these attitudes changed, and the qualitative analysis of the themes that emerged from the open-ended questions, there appears to be evidence to show that participation in an intergenerational choir of college students and people with dementia and their family members has the potential to lay the foundations for a dementia friendly community.

People living with dementia and family members. Each cohort of people with dementia and their family members participated in a focus group. The analytic framework from which the focus group data were examined was organized around the interactions the people with dementia and their family members had with the students in the intergenerational choir.

\section{Cohort 1}

Person with dementia:

"We had such a wonderful experience with the young people. They have sort of an innate feeling about what to do. And watching them do this or that to help us, pointing to where we are on the sheet of music, if we got lost, without being prompted."

"We all need each other. Listening to everyone's stories and singing together makes me feel less alone."

Family member:

"I originally joined the choir as a way to spend some time with my grandmother. She has always been the singer in the family and that is something we liked to do together. I didn't give much thought to the rest of the group. But it has been so much fun, since the first day. There has been an instant group and bonding. It has been really nice paired with the students, I like how that was set up. There has been much more of a group feel than I expected. This has definitely been fun."

\section{Cohort 2}

Person with dementia:

"I expected fear from the students because of not knowing about AD, but they were open and empathetic, and perceived us as, 'We, not them."”

Family member:

"I have found the students to be open and empathetic. When we are here it helps us to focus on what we all can accomplish together." 


\section{Cohort 3}

Person with dementia:

"When I spend time with the students, I feel energized and accepted. It is fun being around young people."

Family member:

"We felt a close connection to the students; I feel we could be family."

\section{Cohort 4}

Person with dementia:

"It's like seeing old friends each week. It's nice to see their exuberance and excitement. I feed on it."

"They are so helpful and once everyone starts singing the differences fade away."

Family member:

"I was surprised how polite and friendly the students are. Not what I expected from college students. I don't feel any kind of barrier like, 'They are just putting up with these old people.'”

Thus, across all the cohorts, by participating in the intergenerational choir the people with dementia and their family members felt accepted, included and welcomed. Some developed friendships with the students. They in essence felt part of a dementia friendly community. Here is a link to the final performance of Cohort 3, which demonstrates that feeling of community: https://youtu.be/f2ZJNA7G6NU.

\section{Discussion and conclusions}

This study was undertaken to see if for four years with four cohorts whether a unique timelimited program, singing in an intergenerational choir composed of undergraduate college students and people with early stage dementia and their family members, could lay the foundations for a dementia friendly community on a college campus. There were many limitations to this study. It was not a randomized control group study. The sample size for each cohort was small. The people with dementia and their family members were associated with the Alzheimer's Association and were support group members, so they may not have represented the diversity among people with early stage dementia. The college students attended a liberal arts college, where concern about issues of social justice was prevalent. However, with all that taken into consideration, the overwhelming evidence presented above demonstrates the potential of something as common place as a choir to assist in building a welcoming community for people with dementia.

The specific objectives of the research study were to: (1) lessen misunderstanding students have about people with dementia; (2) give people with dementia and their family members an opportunity to interact with college students, and teach them about the lived experience of dementia; (3) increase students awareness of the strengths that remain in people with 
early stage dementia; (4) develop meaningful social connections between the choir members that would reach across the barriers of age, disabilities, and abilities; and (5) determine if these findings could be replicated across different cohorts of college students and people with dementia and their family members.

Examining the data presented above, each of these objectives has been met on some level. The students through their qualitative comments and positive change in their descriptor words showed an increased understanding about the lived experience of dementia, a reduction in dementia stigma, and an increase of awareness about the capabilities of people with dementia. In that growth process, the students become much more comfortable interacting and being around people with dementia to the extent that they looked forward to their weekly rehearsals, and many students began to refer to the people with dementia and their family members as "friends." Thus, meaningful social connections were established, the start of a dementia friendly community.

Across the four cohorts, the people with dementia and their family members through participation in the choir had very positive and meaningful interactions with the students. A number of participants rejoined the choir for multiple years. Through these social connections with the college students they felt included, welcomed, valued, and respected. These are the characteristics of a dementia friendly community. The people with dementia and family members too, like the students, talked about the closeness they felt in the choir and the development of friendships.

This research also demonstrated that the findings from the study could be replicated with similar results. Therefore, this study adds to the knowledge base about approaches for building dementia friendly communities (Henwood \& Downs, 2014) and reducing dementia stigma (ADI, 2012). It also supports the findings about the benefits of music as a means to foster social interaction and connectedness (Dowlen et al., 2017; Reynolds et al., 2017).

Knowledge about how to make communities more dementia friendly is in its infancy. But as more and more people with dementia, their family members, and "friends" begin to make their collective voices heard, and demand the respect, inclusiveness, and other rights of citizenship they deserve, the term dementia friendly may one day become as common place as the term family friendly. For isn't that what we all really want, to be treated like family, in the true sense of the word. To be in an environment where one is loved, respected, encouraged, and supported to be one's best. As one of the students in the choir said, "I think I am most surprised by how inspiring this experience has been. I have seen examples of family, love, hope, and determination in places that the stigma would say is all hopeless. It emphasized how important community building is no matter what age or circumstance. It is something I now feel passionate about and am willing to engage in conversation about with others." We all need to be willing to engage in such conversations.

\section{Acknowledgements}

This study would not be possible without the unwavering support of the Cleveland Area Chapter of the Alzheimer's Association, the dedication of the choir members, and a John Carroll University Summer Faculty Research Fellowship.

\section{Declaration of conflicting interests}

The author(s) declared no potential conflicts of interest with respect to the research, authorship, and/or publication of this article. 


\section{Funding}

The authors disclosed receipt of the following financial supportfor the research, authorship, and/or publication of this article: This research was partially supported by a Summer Faculty Research Fellowship from John Carroll University.

\section{References}

Act on Alzheimer's. (2017). Minnesotans working together on the impact of Alzheimer's. Retrieved October 13, 2017, from http://www.actonalz.org/

Allport, G. W. (1954). The nature of prejudice. Reading, MA: Addison Wesley.

Alzheimer's Association. (2017). 2017 Alzheimer's disease facts and figures. Alzheimer's \& Dementia, 13, 325-373.

Alzheimer's Disease International (ADI). (2012). World Alzheimer report: Overcoming the stigma of dementia. London: AD International.

Alzheimer's Disease International (ADI). (2016a). World Alzheimer report: Improving health care for people living with dementia. Retrieved October 1, 2017, from https://www.alz.co.uk/research/ WorldAlzheimerReport2016.pdf

Alzheimer's Disease International (ADI). (2016b). Dementia friendly communities: Key principles. Retrieved from https://www.alz.co.uk/dementia-friendly-communities/resources

Alzheimer's Society. (2013). Building a dementia friendly community: A priority for everyone. Retrieved August 8, 2017, from https://www.alzheimers.org.uk/site/scripts/download_info.pjp?fileID $=1916$

Bartlett, R. (2016). Scanning the conceptual horizons of citizenship. Dementia: The International Journal of Social Research and Practice, 15(3), 453-461. DOI: 19.1177/1471301216644114.

Burnside, L., Knecht, M., Hopely, R., \& Logsdon, R. (2017). Here: Now - Conceptual model of the impact of an experiential arts program on persons with dementia and their care partners. Dementia: International Journal of Social Research and Practice, 16(1), 29-45. DOI: 10.1177/ 1471301215577220 .

Cahill, S., Clark, M., O’Connell, H., Lawlor, B., Coen, R. F., \& Walsh, C. (2008). The attitudes and practices of general practitioners regarding dementia in Ireland. International Journal of Geriatric Psychiatry, (23), 663-669.

Camic, P. M., Williams, C. M., \& Meeten, F. (2013). Does a 'Singing Together Group' improve the quality of life of people with a dementia and their carers? A pilot evaluation study. Dementia, 12 (2), 157-176. DOI: $10.1177 / 1471301211422761$.

Dementia Friendly America. (2017). The dementia friendly America Initiative. Retrieved September 28, 2017, from http://www.dfamerica.org

de Medeiros, K., \& Basting, A. (2013). Shall I compare thee to a dose of donepezil?: Cultural arts interventions in dementia care research. The Gerontologist, 54(3), 344-353. DOI: 10.1093/geront/ gnt055.

Department of Health UK. (2009). Living well with Dementia: A National Dementia Strategy. London: Department of Health.

Dobbs, D., Eckert, J. K., Rubinstein, B., Keimig, L., Clark, L., \& Frankowski, A. C. (2008). An ethnographic study of stigma and ageism in residential care or assisted living. The Gerontologist, 48, $517-526$.

Dowlen, R., Keady, J., Milligan, C., Swarbrick, C., Ponsillo, N., Geddes, L., \& Riley, B. (2017). The personal benefits of musicking for people living with dementia: A thematic synthesis of the qualitative literature. Arts \& Health. Epub ahead of print 2017. DOI: 10.1080/17533015.2017.1370718.

Downs, M. (2013). Putting people - And compassion-first: The UK's approach to person-centered care for individuals with dementia. Generations, 37(3), 53-59.

Goffman, E. (1963). Stigma: Notes on the management of spoiled identity. Englewood Cliffs, NJ: Prentice Hall. 
Grefe, D. (2010). Combating ageism with narrative and intergroup contact: Possibilities of intergenerational connections. Pastoral Psychology, 60(1), 99-105.

Harris, P. B., \& Caporella, C. A. (2014). An intergenerational choir formed to lessen Alzheimer's disease stigma in college students and decrease the social isolation of people with Alzheimer's disease and their family members. American Journal of Alzheimer's Disease \& Other Dementias, 29(3), 270-281.

Hays, T., \& Minichiello, V. (2005). The contribution of music to the quality of life in older people: An Australia qualitative study. Ageing \& Society, 25, 261-278.

Heathrow Press Release. (2017). Heathrow commits to becoming the world's first dementia friendly airport. Retrieved September 18, 2017, from http://mediacentre.heathrow.com/pressrelease/details/ 81/Corporate-operational-24/7146

Henwood, C., \& Downs, M. (2014). Dementia-friendly communities. In M. Downs \& B. Bowers (Eds), Excellence in dementia care: Research into practice (pp. 20-35). New York, NY: McGraw-Hill.

Holstein, J. A., \& Gubrium. (1994). Phenomenology, ethnomethodology, and interpretive practice. In N. K. Denzin \& Y. S. Lincoln (Eds), Handbook of qualitative research (pp. 262-272). Thousand Oaks, CA: Sage.

Justiss, M. D., Boustani, M., Fox, C., Perkins, A. J., \& Healey, P. J. (2009). Patients' attitudes of dementia screening across the Atlantic. International Journal of Geriatric Psychiatry, 24, 632-637.

Kitwood, T. (1997). Dementia re-considered: The person comes first. Buckingham: Open University Press.

Lin, S. Y., \& Lewis. (2015). Dementia friendly, dementia capable, and dementia positive: Concepts to prepare for the future. The Gerontologist, 55(2), 237-244. DOI: 10.1093geront/gnu122.

Loe, M. (2013). The digital life history project: Intergenerational collaborative research. Gerontology \& Geriatrics Education, 34(1), 26-42.

Lundquist, T. S., \& Ready, R. E. (2008). Young adult attitudes toward Alzheimer's disease. American Journal of Alzheimer's Disease \& Dementias, 23(3), 267-273. DOI: 10.1177/1533317508317818.

McDermett, O., Orrell, M., \& Ridder, H. M. (2014). The importance of music for people with dementia: The perspectives of people with dementia, family carers, staff, and music therapists. Ageing \& Mental Health, 18(6), 607-716. DOI: 10.1080/13607863.2013.875124.

Ministry of Health and Care Services. (2008). Dementia plan 2015. Oslo: Ministry of Health and Care Services.

Newman, S., Faux, R., \& Larimer, B. (1997). Children's views on aging: Their attitudes and values. The Gerontologist, 37(3), 412-417.

O'Connor, M. L., \& McFadden, S. H. (2010). Development and psychometric validation of the dementia attitude scale. International Journal of Alzheimer's Disease, (2010), 1-9. DOI:10.4061/ 2010/454218.

Oliver, M. (1990). The politics of disablement. Basingstoke: Palgrave Macmillan.

Reynolds, L., Innes, A., Poyner, C., \& Hambidge, S. (2017). The stigma attached isn't true of real life': Challenging public perception of dementia through a participatory approach involving people with dementia. Dementia: The International Journal of Social Research and Practice, 16(2), 219-225. DOI: $10.1177 / 1471301216635828$.

Robinson, S. M., Canavan, M. O., \& O'Keeffie, S. T. (2014). Preferences of older people for early diagnosis and disclosure of Alzheimer's disease before and after considering potential risks and benefits. Archives of Gerontology and Geriatrics, 59, 607-612.

Sabat, S. (2011). A Bio-Psycho-Social model enhances young adults' understanding of and beliefs about people with Alzheimer's disease: A case study. Dementia, 11(1), 95-112. DOI: 10.1177/ 1471301210392986.

Schutz, A. (1967). The phenomenology of the social world. Evanston, IL: Northwestern University Press.

Schutz, A. (1970). On phenomenology of the social relationships. Chicago, IL: University of Chicago Press. 
Scottish National Health Services. (2010). Scotland's National Dementia Strategy. Retrieved September 29, 2017, from http://www.gov.scot/Publications/2010/09/10151751/0

Sixsmith, A., \& Gibson, G. (2007). Music and the wellbeing of people with dementia. Ageing and Society, 27(1), 127-145.

Swaffer, K. (2015). Dementia and prescribed disengagement. Dementia: International Journal of Research and Social Practice, 14(1), 3-6. Editorial. DOI: 10.1177/147130121454813.

Thompson, E. H., \& Weaver, A. J. (2016). Making connections: The legacy of an intergenerational program. The Gerontologist, 56(5), 909-918. DOI: 10.1093/geront/gnv064.

Unadkat, S., Camic, P. M., \& Vella-Burrows, T. (2016). Understanding the experience of group singing for couples where one partner has a diagnosis of dementia. The Gerontologist, 57, 469-478. DOI: $10.1093 /$ geront/gnv698.

US Department of Health and Human Services. (2012). National Plan to Address Alzheimer's Disease. Retrieved September 29, 2017, from aspe.hhs.gov/national-plan-address-alzheimers-disease-andother-napadocuments

Vernooji-Dassen, M. J. F., Moniz-Cook, E. D., Woods, R. T., De Lepeleire, J., Leuschner, A., \& Zanetti, O. (2005). Factors affecting timely recognition and diagnosis of dementia across Europe: From awareness to stigma. International Journal of Geriatric Psychiatry, 20, 377-386.

Watson, J. (2016). Is it possible to live well with dementia? Dementia: International Journal of Research and Social Practice, 15(1), 4-5. Editorial. DOI: 10.1177/1471301215616324.

Werner, P., \& Heinik, J. (2008). Stigma by association and Alzheimer's disease. Aging and Mental Health, 12(1), 92-99.

World Health Organization and Alzheimer's Disease International (WHO/ADI). (2012). Dementia: A public health priority. Geneva: WHO.

Phyllis Braudy Harris, PhD, ACSW, LISW is a professor of Sociology \& Criminology, and director of the Aging Studies at John Carroll University, Cleveland, Ohio. She is a fellow of the Gerontological Society of America, and is the founding co-editor of Dementia: The International Journal of Social Research and Practice. Her research focuses on understanding the psychosocial impact of dementia on persons living with early stage dementia and their family members, with the goal of assisting these individuals to develop coping strategies to continue to live meaningful lives, as well as to increase public awareness about dementia.

Cynthia Anne Caporella, PhD is the director of Liturgical Music and Musical Arts at John Carroll University, Cleveland, Ohio. 